\title{
3D PHOTOGRAMMETRIC PROCESSING OF WORLDVIEW-2 DATA WITHOUT GCP
}

\author{
Th. Toutin ${ }^{\mathrm{a}, *}$, C.V. Schmitt ${ }^{\mathrm{a}}$, H. Wang ${ }^{\mathrm{a}}$, P. Reinartz \\ ${ }^{a}$ Canada Centre for Remote Sensing, 588 Booth St., Ottawa, K1A 0Y7, Canada - (toutin, schmitt, wang)@nrcan.gc.ca \\ ${ }^{\mathrm{b}}$ DFD-DLR German Aerospace Center, D-82234 Oberpfaffenhofen, Germany - Peter.Reinartz@dlr.de
}

Commission I, WG I/4

KEY WORDS: Photogrammetry, Satellite, WorldView-1, 3D Modeling

\begin{abstract}
:
A hybrid model based on 3D deterministic Toutin's model developed at the Canada Centre for Remote Sensing and taking full advantages of the image metadata was used for the 3D photogrammetric processing of WorldView-1 stereo images without in situ ground control points (GCP) collection. The accuracy of the modelling results in monoscopy and stereoscopy was around $0.7-1.8 \mathrm{~m}$ in planimetry and $2.7 \mathrm{~m}$ in altimetry computed over $40 \mathrm{dGPs}$ checked points. Elevations were thus extracted and compared to $0.2-\mathrm{m}$ accurate lidar elevation data. Elevations linear error with 68 percent confidence level (LE68) computed over bare surfaces was 2.6 $\mathrm{m}$, with small biases. These results were compared with the solution using 8 dGPS GCPs and demonstrated there is no significant difference in accuracy. Consequently, the new hybrid model will offer a strong advantage of no-control collection in operational conditions, mainly in remote and harsh environments or when cartographic or ground control data do not exist.
\end{abstract}

\section{INTRODUCTION}

\subsection{General Instructions}

Due to the high spatial resolution (HR) of recent spaceborne optical sensors, a large number of researchers have investigated satellite photogrammetric methods using deterministic modeling, mainly based on colinearity and coplanarity conditions (Toutin, 2011). More recently, preliminary results of digital surface model (DSM) generation from WorldView-1 (WV-1) panchromatic stereo-data were presented using two deterministic models and geometrically-constraint area-based matching algorithm (Capaldo et al., 2012). Good results in elevation when compared to lidar data were obtained in open areas $(1.7 \mathrm{~m}, 1 \sigma)$ but worse in urban areas $(3-5 \mathrm{~m}, 1 \sigma)$.

On the other hand, an empirical modeling (Okamoto, 1981), 3D rational function model (RFM), as an alternative to avoid the development of deterministic models has been re-popularized since 2002 (Madani, 1999, Tao and Hu, 2002). The advantages of this "universal real time image geometry model", (universality, confidentiality, efficiency and information transfer), as well as the disadvantages (loss of accuracy, numerical instability, failure for highly-distorted imagery, uncertainty, and complexity) were largely discussed since its first applications (Dowmann and Dolloff, 2000). Digital Globe (DG) and MacDonald, Dettwiler and Associates Ltd. (MDA) developed a dynamic $3^{\text {rd }}$-degree RFM for WorldView-1, which largely reduced some of these previous disadvantages. It also has accuracy close to their 3D deterministic model after calibration and validation.

Research works for DSM generation from WV-1 were then performed using RFM post-processed with different 2D polynomial functions and different image matching algorithms (Cheng and Chaapel, 2008, Poli et al., 2009). In general, the achieved elevation accuracies are relatively equivalent: around $2-5 \mathrm{~m}(1 \sigma)$ depending on land cover and slopes, and of course on the base-to-height ratio $(\mathrm{B} / \mathrm{H})$, which unfortunately can largely vary $(0.5-1)$ with no control by users.

The principal objectives of this research paper are to combine the synergy of both deterministic and empirical models into a "new hybrid" model in order to eliminate the GCP collection task, and to apply it to WV-1 stereo data acquired over a hilly study site, north of Québec City, Quebec.

\section{STUDY SITE AND DATA SET}

\subsection{Study Site}

The study site is located north of Québec City, Québec, Canada $\left(47^{\circ} \mathrm{N}, 71^{\circ} 30^{\prime} \mathrm{W}\right)$ and spans different environments: urban and residential, semi-rural and forested. The elevation ranges almost from $100 \mathrm{~m}$ in the city in the southeast to around $600 \mathrm{~m}$ in the Canadian Shield in the north. The northern part is a hilly topography $\left(5^{\circ}-25^{\circ}\right.$ slopes $)$ mainly covered with forests (deciduous, conifer and mixed) while the south part is a semiflat topography $\left(0^{\circ}-5^{\circ}\right.$ slopes $)$ with urban and residential areas.

\subsection{WorldView-1}

The data set included two stereo pairs (roughly 20 by $24 \mathrm{~km}$ ) from WV-1 acquired July 10, 2009 with asymmetrical mean offnadir view angles of $-34.1 \%+18.6^{\circ}$ generating $\mathrm{B} / \mathrm{H}$ ratio in the epipolar plane of 1.01. Each image of the stereo-pair is provided into two sub-images with a line overlap (Fig 1), which thus required a stitching processing to generate the final image. Unfortunately, the stereo-pair only covered the easteren part of the study site. The data were pre-processed as basic 1B product (16 bits), orbit oriented with a pixel spacing of $0.5-0.7 \mathrm{~m}$

\footnotetext{
* Corresponding author.
} 
depending on each product. The metadata were provided in separate files, which included RFM with its 80 coefficients for each image.
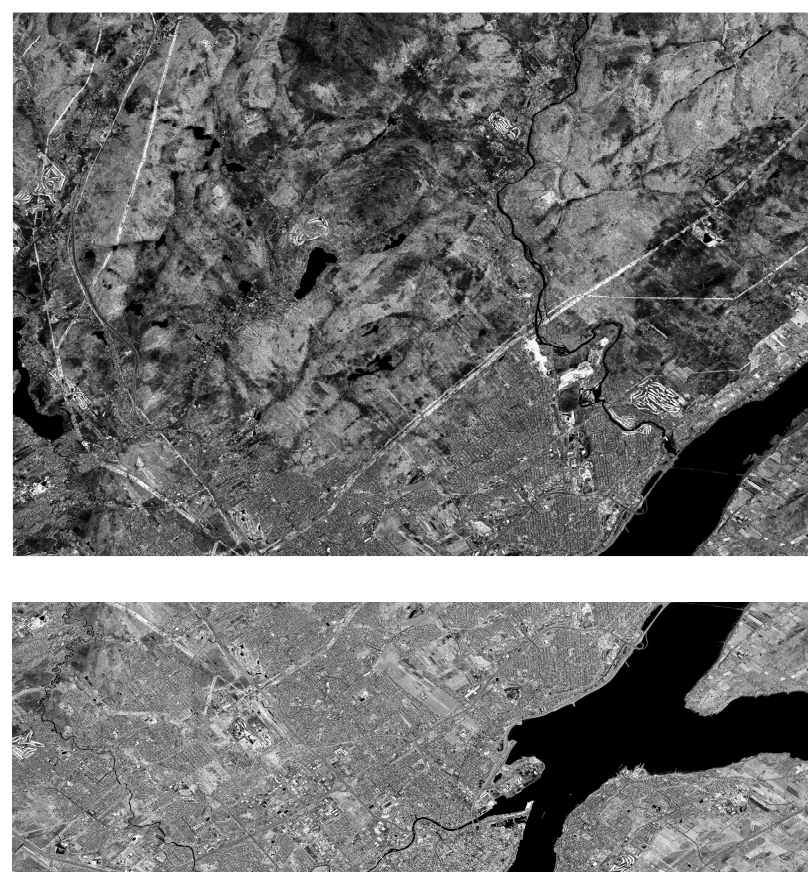

Figure 1. WorldView-1 forward sub-images (Top: northern area; Below: southern area) with around 4000-line overlap, acquired July 10 2009, north of Québec City, Quebec, Canada.

WorldView-1 Data @ and courtesy DigitalGlobe (2009).

\subsection{Cartographic Data}

The reference cartographic data included ground points (about 40 ), mainly road features and electrical poles collected from a differential Global Positioning System (dGPS) survey in November 2008 with 3-D ground accuracy better than $10 \mathrm{~cm}$. The collected points were used as independent check points (ICPs) to quantify/validate the hybrid model In addition, accurate spot elevation data (first and last echoed returns; around one point per $\mathrm{m}^{2}$ ) were obtained on April 2010 from a lidar survey collected. Both echoed returns were used to generate 1-m pixel digital elevation model and DSM (Fig 2), which integrated the heights of surface features. The positioning and elevation accuracy checked versus the previous dGPS was better than $30 \mathrm{~cm}$ and $20 \mathrm{~cm}$, respectively. These points are only used as independent check points (ICPs) of the hybrid models.

\section{3D PHOTOGRAMMETRIC PROCESSING}

\subsection{The Hybrid Model}

The "new hybrid" deterministic model is based on Toutin's deterministic model and used RFM to compute "virtual" control points (VCPs) for replacing control points (CPs) collected by the users. A planimetric grid with 500-pixel spacing approximately is generated and random elevations comprised between an estimated minimum and maximum elevations of the imaged terrain is assigned. These 3D VCPs thus avoided any extrapolation in planimetry and altimetry. For stereo-images VCPs were the same for each image and in addition used as tie points.

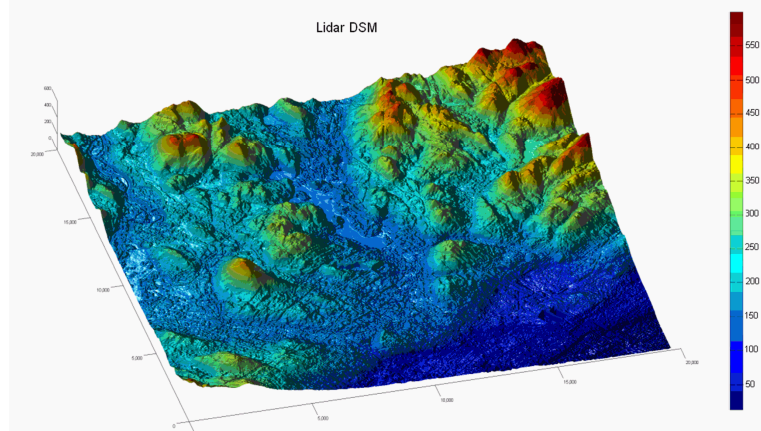

Figure 2. South-to-north perspective viewing of lidar DSM with colour-coded elevations ( $0 \mathrm{~m}$ at blue and around 600 $\mathrm{m}$ at red)

\subsection{Photogrammetric steps}

The steps for the photogrammetric processing with WV stereoimages are more and less the same than for digital aerial photos. The main processing steps are: (1) The acquisition of the stereo-images and metadata; (2) The collection on WV-1 stereo-images of 40 ICPs, respectively from dGPS survey (10$\mathrm{cm}$ 3D accuracy); (3) The computation with VCPs the hybrid model and the evaluation with ICPs; (4) The elevation extraction with area-based image matching, its edition and geocoding. Finally, the geocoded DEM is compared to Lidar data to quantify the elevation accuracy.

\section{RESULTS AND ANALYSIS}

\subsection{Accuracy analysis of the hybrid models}

Table 1 summarizes the results of hybrid-model computation with VCPs as CPs and tie points in monoscopy and stereoscopy: the errors (bias, standard deviation, Std, min./max in metres) computed on dGPS ICPs (40) providing independent and unbiased evaluations of the modeling accuracy. Some biases (3-4 m) for both modes (mono-/stereoscopy) remained, mainly in X-direction. Because no bias was found with the deterministic Toutin's model computed with dGPS GCPs on a previous experiment (not shown in this paper), it can be concluded that this systematic error on the hybrid model results came from a small systematic errors in the metadata (certainly from the orbit). However, these biases can be easily corrected using water bodies afterwards when integrating the orthoimages with other cartographic data or in the stereo model. On the other hand, the random planimetric errors are the same (1-2 $\mathrm{m})$ but a part is also due to the plotting error (1-2 pixels) of ICPs on the WV images.

\begin{tabular}{|l|c|c|}
\hline WV-1 & Bias (m) & Std (m) \\
\hline & $\mathrm{X}, \mathrm{Y}, \mathrm{Z}$ & $\mathrm{X}, \mathrm{Y}, \mathrm{Z}$ \\
Fore & $4.4,-1.9, \mathrm{~N} / \mathrm{A}$ & $1.8,1.5, \mathrm{~N} / \mathrm{A}$ \\
Aft & $3.1,-0.6, \mathrm{~N} / \mathrm{A}$ & $0.9,1.7, \mathrm{~N} / \mathrm{A}$ \\
Stereo & $3.8,1.8,-1.1$ & $1.4,0.7,2.7$ \\
\hline
\end{tabular}

Table 1. Hybrid model results computed on dGPS ICPs: bias and standard deviation (Std) in metres

\subsection{DSM Results}

In general, the DSM (Fig 3) well describes the macrotopography and the macro linear trends with mountains and 
valleys, enhancing the structural geological framework. The mountains and valleys are generally smooth, being a good representation of a Precambrian geomorphology (smoothedglacial and eroded topography). The main largest black areas correspond to the mismatched areas related to the different water bodies (the St-Lawrence River can be recognized at the right). Some also are located in the north-east oriented mountains slopes, which correspond to occluded areas with westward $34^{\circ}$ and $18^{\circ}$ viewing angles. The matching well worked in the urban areas because there are very few mismatched areas (bottom right). While our system used traditional area-based image matching, better qualitative matching results could have been obtained when using more recent algorithms (Hirschmüller, 2008), not presently developed at CCRS, but which are better adapted to HR optical data (d'Angelo and Reinartz, 2011).

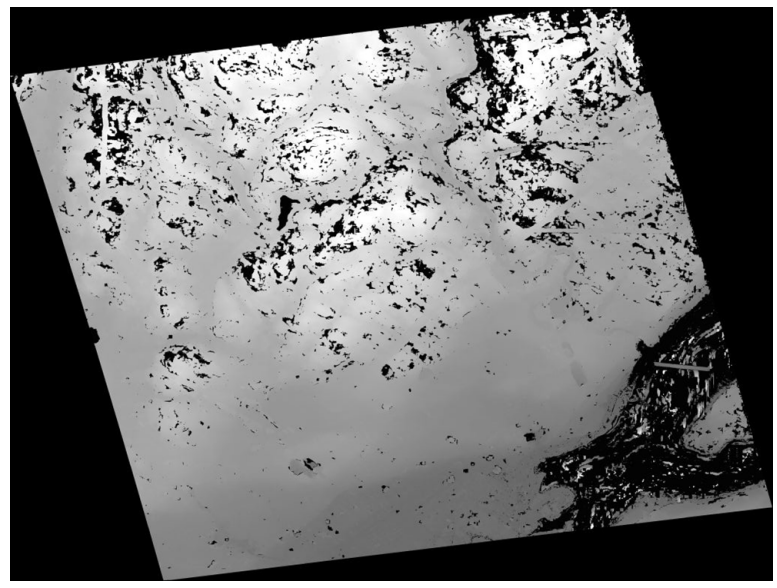

Figure 3. WorldView-1 geocoded DSM (north oriented; 2-m spacing).

After removing the small planimetric biases previously computed on ICPs, the evaluations were performed over the coverage of the lidar data, being on the half western part of WV-1. : all relief (flat to mountainous; all slopes and azimuths) and all land covers (urban, semirural, bare soils, and forested areas) of the study site were embraced. Table 2 shows the statistical results of the stereo-extracted DSM with lidar elevation. The results (number of used points in the statistics, bias, linear elevation errors with 68 and $90 \%$ levels of confidence) were first computed over all land covers (first line). The small bias suggests that there is no systematic difference between lidar and WV elevations. In addition, LE68 and LE90 still give a good idea of the potential accuracy (elevation plus height) whatever the land cover but more specifically over forested areas, which correspond to $70 \%$ of the site.

Table 2. DSM evaluated with Lidar: bias, LE68 and LE90

\begin{tabular}{|l|c|c|c|c|}
\hline $\begin{array}{l}\text { WV-1 } \\
\text { Surfaces }\end{array}$ & $\begin{array}{c}\text { No. of used } \\
\text { points }\end{array}$ & $\begin{array}{c}\text { Bias } \\
(\mathrm{m})\end{array}$ & $\begin{array}{c}\text { LE68 } \\
(\mathrm{m})\end{array}$ & $\begin{array}{c}\text { LE90 } \\
(\mathrm{m})\end{array}$ \\
\hline All & 40585923 & 0.4 & 3.3 & 6.2 \\
\hline Bare & 26317210 & -0.3 & 2.6 & 4.6 \\
\hline
\end{tabular}

However, the footprint and the viewing angles between the lidar (10 $\mathrm{cm}$ and nadir viewing) and WV-1 data acquisition system (50 $\mathrm{cm}$ and off-nadir viewing) were different and therefore resulted in different penetration levels in forest areas, which thus recorded different elevation points. Resulting errors were thus induced in systematic and random errors of the accuracy analysis over all surfaces. Consequently, the true DSM accuracy was measured over bare surface (soils and paved areas) where the same elevation points between lidar and WV are recorded and compared. The bare surfaces results show better results $(20 \%)$ than the previous results over all surfaces: no bias and the potential to generate $10-\mathrm{m}$ contour lines with A1 standard.

While the errors are slightly larger (10\%) when compared to the solution using dGPS GCPs (not shown in this paper), this reduction of accuracy is compensated by the gain of processing stereo-images and generating DSMs with no GCP collected by users, which increases the applicability of WV-1 to remote areas and study sites without any cartographic or ground control data.

\section{CONCLUSIONS}

Because GCP collection is a difficult and expensive task in the 3D geometric modelling of HR images, especially remote and harsh environments, the impact of using only the metadata instead of GCPs was evaluated of elevation extraction from WV-1 stereo data acquired over a residential/rural hilly area in Quebec, Canada. The stereo-extracted elevations were then compared to accurate lidar elevation data. LE68 of $3.3 \mathrm{~m}$ and $2.6 \mathrm{~m}$ with almost no bias were achieved over all surfaces and bare surfaces, respetively. While the geometric solution with no GCP achieved slightly less accurate results, but not significantly, than the solution with eight (8) accurate GCPs, this accuracy reduction is compensated by the gain of not using any GCP to compute the stereo-model and to extract elevation. This new capability will certainly increase the use and the applicability of WV to remote areas and study sites without any cartographic or ground control data.

\section{Acknowledgements}

The authors thank Digital Globe for providing WorldView-1 stereo-images and Dr. Philip Cheng of PCI Geomatics for the integration of this hybrid model and algorithm into their Geomatica software.

\section{References}

d'Angelo, P., Reinartz, P., 2011. Semiglobal Matching Results on the ISPRS Stereo Matching Benchmark. International Archives of Photogrammetry and Remote Sensing and Spatial Information Sciences, Vol. XXXVIII, Part 4/W19, CD-ROM.

Capaldo, P., Crespi, M., Fratarcangeli, F., Nascetti, A., Pieralice, F., 2012. DSM generation from high resolution satellites imagery: applications with WorldView-1 and GeoEye1, Italian Journal of Remote Sensing, (in press).

Cheng, Ph., Chaapel, C., 2008. Using WorldView-1 Stereo Data with or without Ground Control Points. GEOinformatics, 11(7), pp. 34-39

Dowmann I., Dolloff, J., 2000. An evaluation of rational function for photogrammetric restitution. International Archives of Photogrammetry \& Remote Sensing, 33 (Part B3), pp. 254266. 
Hirschmüller, H., 2008. Stereo processing by semi-global matching and mutual information. IEEE Transactions on Pattern Analysis and Machine Intelligence, 30(2), pp. 328 341.

Madani, M., 1999. Real-Time Sensor-Independent Positioning by Rational Functions. ISPRS Workshop on Direct Versus Indirect Methods of Sensor Orientation, pp. 64-75.

Okamoto, A., 1981. Orientation and Construction of Models. Part III: Mathematical Basis of the Orientation Problem of One-

Dimensional Central Perspective Photographs. Photogrammetric Engineering and Remote Sensing, 47, pp. 1739-1752.

Poli, D., Wolff, K., Gruen, A., 2009. Evaluation of Worldview1 stereo scenes and related 3D products. International Archives of the Photogrammetry, Remote Sensing and Spatial Information Sciences, Vol. 38, Part 1-4-7/W5.

Tao, V., Hu, Y., 2002. 3D reconstruction methods based on rational function model. Photogrammetric Engineering \& Remote Sensing, 68(7), pp. 705-714.

Toutin, Th., 2011. State-of-the-art of geometric correction of remote sensing data: a data fusion perspective. International Journal of Image \& Data Fusion, 2(1), pp. 3-35. 